\title{
Corrigendum: The Impact of Global Dynamic Capabilities on Governance Structure Choice of Partnership: The Moderating Effect of Ambidexterity
}

\section{OPEN ACCESS \\ Approved by: \\ Frontiers Editorial Office, \\ Frontiers Media SA, Switzerland \\ ${ }^{*}$ Correspondence: \\ Michael Yao-Ping Peng \\ s91370001@mail2000.com.tw \\ †These authors have contributed equally to this work and share first \\ authorship \\ Specialty section: This article was submitted to \\ Organizational Psychology, \\ a section of the journal \\ Frontiers in Psychology \\ Received: 12 March 2021 \\ Accepted: 30 June 2021 \\ Published: 05 October 2021 \\ Citation: \\ Ren G and Peng MY-P (2021) Corrigendum: The Impact of Global Dynamic Capabilities on Governance Structure Choice of Partnership: The Moderating Effect of Ambidexterity \\ Front. Psychol. 12:679604. doi: 10.3389/fpsyg.2021.679604}

\section{Guoying Ren ${ }^{1 \dagger}$ and Michael Yao-Ping Peng ${ }^{2 \star \dagger}$}

${ }^{1}$ Business School, Beijing Normal University, Beijing, China, ${ }^{2}$ School of Economics \& Management, Foshan University, Foshan, China

Keywords: global dynamic capabilities, Governance structure, learning orientation, market orientation, international marketing

\section{A Corrigendum on}

The Impact of Global Dynamic Capabilities on Governance Structure Choice of Partnership: The Moderating Effect of Ambidexterity

by Ren, G., and Peng, M. Y.-P. (2021). Front. Psychol. 12:619334. doi: 10.3389/fpsyg.2021.619334

In the original article, there was an error in the authorship as published. After a unanimous decision, the authors consider that Din Jong had a low contribution to this article and is not qualified to be an author of this article. Thus, the author Din Jong has been removed from the author list.

The authors apologize for this error and state that this does not change the scientific conclusions of the article in any way. The original article has been updated.

Publisher's Note: All claims expressed in this article are solely those of the authors and do not necessarily represent those of their affiliated organizations, or those of the publisher, the editors and the reviewers. Any product that may be evaluated in this article, or claim that may be made by its manufacturer, is not guaranteed or endorsed by the publisher.

Copyright (c) 2021 Ren and Peng. This is an open-access article distributed under the terms of the Creative Commons Attribution License (CC BY). The use, distribution or reproduction in other forums is permitted, provided the original author $(s)$ and the copyright owner(s) are credited and that the original publication in this journal is cited, in accordance with accepted academic practice. No use, distribution or reproduction is permitted which does not comply with these terms. 